\title{
Maternal lysozyme concentrations in the eggs of the Great Cormorant (Phalacrocorax carbo) in relation to breeding density and laying order
}

\author{
Jian Cao ${ }^{1,2}$, Jirong $\mathrm{Li}^{1,2}$, Wen Wang ${ }^{3}$, Fang Yang ${ }^{1}$, Zhuo $\mathrm{Li}^{1}$ and Laixing $\mathrm{Li}^{1 *}$
}

\begin{abstract}
Background: Females can differentially deposit the immune factor lysozyme into eggs based on conditions of local breeding density and laying order.

Materials: We collected 80 eggs from Great Cormorants (Phalacrocorax carbo) and then analyzed whether the level of lysozymes in the eggs is related to breeding density and laying order.

Results: Between clutches, the level of lysozyme in eggs is positively related to breeding density; while within a clutch, the level of lysozyme is positively related to the laying order.

Conclusion: When parents breed under conditions of high density, they allocate more lysozymes to their offspring, a trait adaptive to the local environment. That the increase in the level of lysozymes is a function of the laying order seems a necessary condition to mitigate the hierarchy among siblings for improving the survival of the entire clutch.
\end{abstract}

Keywords: Great Cormorant, Innate immunity, Breeding density, Laying order, Lysozyme, Phalacrocorax carbo,

Survival

\section{Background}

It is well known that birds and other vertebrates nest in colonies during the breeding season. The benefit of colonial breeding is obvious, especially in defending against predators and for forging food (Götmark and Andersson 1984; Danchin and Wagner 1997). But this comes at the cost of enhancing trans-shell infection by parasites, because the number of pathogenic parasites is closely related to nest density (Brown and Brown 1986; Tella 2002). In birds, adults have evolved an array of specific morphological, physiological and behavioral mechanisms to cope with parasites (Kaplan 1985; Mousseau and Fox 1998), but the most effective mechanism is their own immune system which is composed of two different

\footnotetext{
*Correspondence: Ixli@nwipb.cas.cn

${ }^{1}$ Key Laboratory of Adaptation and Evolution of Plateau Biota, Northwest Institute of Plateau Biology, Chinese Academy of Science, 810001 Xining, China

Full list of author information is available at the end of the article
}

branches: innate immunity responses are relatively rapid, non-specific defenses while acquired immunity responses are typically slower and highly pathogen-specific (Klasing and Leshchinsky 1999). However, the immune system of chicks at their early stage is immature and the chicks are virulently vulnerable to pathogenic parasites. To compensate for this parents can, to a considerable extent, affect the survival of their offspring by transmitting immune factors into eggs via maternal effects (Pastoret et al. 1998).

Avian eggs contain a network of immune factors: immunoglobulin, which represents acquired immunity, is mainly transmitted into the yolk via specific responses to pathogens (Kowalczyk et al. 1985); lysozyme which is the major component of their innate immunity and transmitted into the albumen can protect the chick from parasites by digesting the peptidoglycan of the cell walls of bacteria (Javurkova et al. 2015). 
Females could, therefore, deposit different levels of lysozyme in the eggs of neonatal birds to resist the local parasitic environment, because the various kind of parasites are dependent on the breeding density, which varies among nest sites (Brown and Brown 1986; Tella 2002).

Indeed, a previous study has shown that females declined lysozyme in plasma before laying egg and that the clutch size is negatively related to lysozyme concentrations (Saino et al. 2002). This suggests that egg lysozymes derive from the mother whose production of female lysozyme is limited and hence females may deposit lysozyme in eggs differentially within a clutch. There are only few references in the current literature about the allocation of lysozyme into eggs, of which some suggests stability (Shawkey et al. 2008; D’Alba et al. 2010) and the rest shows a decreased allocation in the laying sequence (Saino et al. 2002).

In this study, our first objective was to investigate the relationship between breeding density and lysozyme levels in eggs of the Great Cormorant (Phalacrocorax carbo) and secondly we wanted to analyze the variation in the level of lysozyme with the sequence of laying eggs within a clutch. This variation may reflect the performance of chicks in the future.

\section{Methods}

\section{Field methods}

Our study was carried out in a breeding colony of Great Cormorants (Phalacrocorax carbo) from April to May of 2013, located on an island in Qinghai Lake $\left(36^{\circ} 58^{\prime} \mathrm{N}\right.$, $\left.99^{\circ} 54^{\prime} \mathrm{E}\right)$. The Great Cormorant is a migratory bird, nesting on this island on cliffs and an ichthyophagous bird of the Pelecaniformes. The species is monogamous, asynchronous with a mean clutch size of four. Both parents take turns on incubation which lasts for 28 days, after which the offspring will be fed until 60 days before fledging.

In our daily detection work, eggs were marked according to the order of laying, then each day collected between 18:00 and 19:00 h. We determined the breeding density by the number of nests within a radius of $3 \mathrm{~m}$ around one particular nest. The eggs collected replaced with dummy eggs to prevent females from abandoning their nests. Egg length and breadth were measured with a caliper, to the nearest $0.1 \mathrm{~mm}$ and weight was measured with a balance with an accuracy of $0.1 \mathrm{~g}$. Egg volumes were estimated by Hoyt's formula, i.e., volume $=$ length $\times$ breadth $^{2} \times 0.51$. The collected eggs were then cracked open in a bio-safety cabinet entirely under sterile conditions. The yolk was separated from the albumen by using sterile pipettes and the albumen was stored at $-20^{\circ} \mathrm{C}$.

\section{Lysozyme assay}

Our lysozyme assay consisted of four steps (Shawkey et al. 2008). (1) We put $25 \mathrm{mg}$ of dried Micrococcus lysodeikticus (Sigma) in a $50 \mathrm{~mL} 1 \%$ agar solution (Sangon Biotech Ltd) and cultivated the suspension at a temperature of $50{ }^{\circ} \mathrm{C}$. (2) We then mixed $150 \mu \mathrm{L}$ of this suspension with each $10 \mu \mathrm{L}$ albumen sample on a 96-well plate. The standard curve is obtained by adding the bacterial suspension to serial dilutions of a standard lysozyme solution (Sigma). (3) In our third step plates were incubated overnight at room temperature and absorbance was measured with a Versamax microplate reader at a $850 \mathrm{~nm}$ wavelength. (4) In the end, we calculated the concentration of lysozymes in each sample by a standard curve. All tests were repeated three times to ensure the accuracy of the results (RSD $<2.5 \%)$.

\section{Ethical considerations}

All of our research was carried out with the approval of the Wildlife Service of the Qinghai Forestry Department, by collecting permits from the Qinghai Lake National Nature Reserve. We will remove all dummy eggs immediately after clutch completion to minimize the impact on the populations.

\section{Statistical data analysis}

All statistical data were performed in SPSS 20.0. We used one way ANOVA to test the variation between the laying order and lysozyme concentrations. Correlation analysis was carried out in order to investigate the relationship between the concentration of lysozyme and nests density.

\section{Results}

Our results revealed that the concentration of lysozyme increased with the laying order $(F=9.950$, $p=0.001<0.05$, Fig. 1), with the last egg laid having

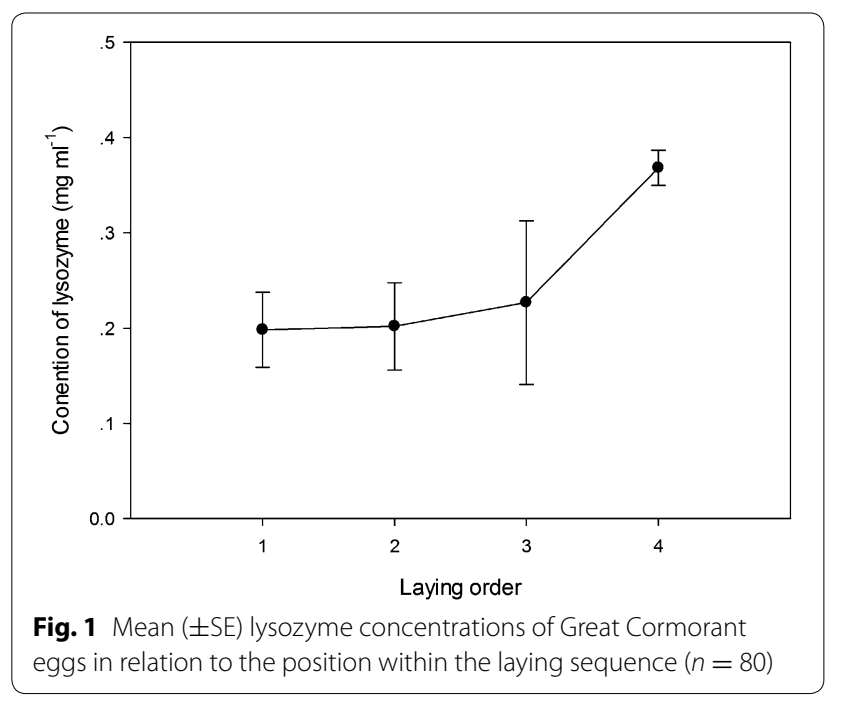


the highest lysozyme level. The difference of lysozyme between the first three eggs was also significant $(F=5.43$, $p=0.041<0.05)$. The variation between lysozyme and the laying order was independent of egg weight $(F=1.09$, $p=0.31)$ and egg volume $(F=0.84, p=0.36)$, while the level of lysozyme between clutches is positively related to nests density $(R=0.8832, p<0.0001$, Pearson correlation).

\section{Discussion}

\section{Between-clutch variation}

From the results, we found the levels of lysozyme to be positively correlated to breeding density. In eggs, lysozyme not only contributes to physical defense but also to chemical defense (Trziszka 1994), hence higher concentrations of lysozyme may reflect stronger protection of eggs against parasites during embryo development. The number of pathogenic parasites has demonstrated close correlation with breeding density, so it may be adaptive for birds to deposit more lysozyme in eggs when breeding density is high.

Alternatively, the relationship between levels of lysozyme and breeding density may be a reflection of good health in females. The Great Cormorant in Qinghai Lake migrates long distances and then breeds in Qinghai Lake. According to our observations, the early arrivals always nested in the center of a colony. Since the level of lysozyme in females decreases before laying eggs, the higher levels of lysozyme in the center is consistent with the condition of the female.

\section{Within-clutch variation}

Our results show that the lysozyme concentration increases with the laying sequence within a clutch, in contrast to the result in barn swallows (Saino et al. 2002). Most birds have to incubate before clutch completion, which causes asynchronously hatching (Clark and Wilson 1981; Stoleson and Beissinger 1995), because the first-laid eggs stay longer in the nest than those laid the last and are easily infected by parasites (Cook et al. 2005). Consequently, a hierarchy of size or body mass among siblings is established. The mother can deposit various kinds of substances in eggs to mitigate or enhance the hierarchy in the: steroid hormones of her brood (Schwabl 1993; Lipar and Ketterson 2000; Eising et al. 2001), carotenoids (Blount et al. 2002; Saino et al. 2002) in egg yolk and lysozyme in egg albumen (Saino et al. 2002). Two of the most important theories can be invoked to explain the significance of different allocations: one is the broodreduction theory which posits that parents transmit more resources into the first-laid eggs to enhance their reproductive value when food is scarce (Vinuela 1997; Gil et al. 1999); the other is the brood-survival theory suggesting that parents mitigate the disadvantages of the younger members of the clutch to improve the survival of whole brood (Schwabl 1997; Lipar et al. 1999). Our results may provide some evidence for the brood-survival theory. Although there is no direct evidence that lysozyme can improve the viability of offspring, the levels of lysozyme in neonatal birds before 12 days is mainly derived maternally. Hence, the fact that females invest more lysozyme in the last-laid eggs not only provides more effective defense for the last-laid eggs but also can help the lasthatched birds to save more resources in order to catch up with their siblings.

The allocation of lysozyme on the basis of the local environment and the combination of asynchronous hatching with differential lysozyme allocation within a clutch, will allow mothers to improve the survival probability of the entire brood. This may be adaptive for birds, but in the future we should invest more resources to investigate how lysozyme affects the survival of birds.

\section{Authors' contributions}

LL designed the experiments and JC conducted the experiments. JC, JL WW

FY and ZL analyzed the data and finished the earlier draft of the manuscript.

All authors read and approved the final manuscript.

\section{Author details}

${ }^{1}$ Key Laboratory of Adaptation and Evolution of Plateau Biota, Northwest Institute of Plateau Biology, Chinese Academy of Science, 810001 Xining, China.

${ }^{2}$ University of Chinese Academy of Science, 100049 Beijing, China. ${ }^{3}$ Sichuan University, 610065 Chengdu, China.

\section{Acknowledgements}

We thank the entire staff of the Qinghai Lake National Nature Reserve for its assistance when we worked in the field, as well as Krill, Shouyang Du, Chao Ma and Xuze Zhang for their help in the laboratory. We are grateful to Shuli Liu whose advice improved significantly the data analysis. This study was financially supported by the State Forestry Administration Program (Grant Nos. Y31/351B01), the National Natural Science Foundation of China (Grant Nos. Y011331501), the National Science \& Technology Pillar Program (Grant Nos. 2008BADB0B0303) and National Basic Research Program of China (Grant Nos. 2010CB530301).

\section{Competing interests}

The authors declare that they have no competing interests.

Received: 7 April 2015 Accepted: 9 October 2015

Published online: 20 November 2015

\section{References}

Blount JD, Surai PF, Nager RG, Houston DC, Møller AP, Trewby ML, Kennedy MW. Carotenoids and egg quality in the lesser black-backed gull Larus fuscus: a supplemental feeding study of maternal effects. Pro R Soc Lond B Bio Sci. 2002;269:29-36.

Brown CR, Brown MB. Ectoparasitism as a cost of coloniality in cliff swallows (Hirundo pyrrhonota). Ecology. 1986;67:1206-18.

Clark AB, Wilson DS. Avian breeding adaptations: hatching asynchrony, brood reduction, and nest failure. Q Rev Biol. 1981;56:253-77.

Cook MI, Beissinger SR, Toranzos GA, Arendt WJ. Incubation reduces microbial growth on eggshells and the opportunity for trans-shell infection. Ecol Lett. 2005;8:532-7.

Danchin E, Wagner RH. The evolution of coloniality: the emergence of new perspectives. Trend Ecol Evol. 1997;12:342-7. 
D'Alba L, Shawkey MD, Korsten P, Vedder O, Kingma SA, Komdeur J, Beissinger SR. Differential deposition of antimicrobial proteins in blue tit (Cyanistes caeruleus) clutches by laying order and male attractiveness. Behav Ecol Sociobiol. 2010;64:1037-45.

Eising CM, Eikenaar C, Schwabl H, Groothuis TG. Maternal androgens in blackheaded gull (Larus ridibundus) eggs: consequences for chick development. Proc R Soc Lond B Biol Sci. 2001;268:839-46.

Gil D, Graves J, Hazon N, Wells A. Male attractiveness and differential testoster one investment in zebra finch eggs. Science. 1999;286:126-8.

Götmark F, Andersson M. Colonial breeding reduces nest predation in the Common Gull (Larus canus). Anim Behav. 1984;32:485-92.

Javurkova V, Krkavcova E, Kreisinger J, Hyrsl P, Hyankova L. Effects of experimentally increased in ovo lysozyme on egg hatchability, chicks complement activity, and phenotype in a precocial bird. J Exp Zool A Ecol Genet Physiol. 2015; 323:497-505.

Kaplan RH. Maternal influences on offspring development in the California newt, Taricha torosa. Copeia. 1985:4:1028-35.

Klasing K, Leshchinsky T. Functions, costs, and benefits of the immune system during development and growth. Ostrich. 1999;69:2817-32.

Kowalczyk K, Daiss J, Halpern J, Roth T. Quantitation of maternal-fetal IgG transport in the chicken. Immunology. 1985;54:755-62.

Lipar JL, Ketterson ED, Nolan V. Intraclutch variation in testosterone content of red-winged blackbird eggs. Auk. 1999;116:231-5.

Lipar JL, Ketterson ED. Maternally derived yolk testosterone enhances the development of the hatching muscle in the red-winged blackbird Agelaius phoeniceus. Proc R Soc Lond B Biol Sci. 2000;267:2005-10.
Mousseau TA, Fox CW. The adaptive significance of maternal effects. Trend Ecol Evol. 1998;13:403-7.

Pastoret PP, Griebel P, Bazin H, Govaerts A. Handbook of vertebrate Immunology. California: Academic Press; 1998

Saino N, Bertacche V, Ferrari RP, Martinelli R, Møller AP, Stradi R. Carotenoid concentration in barn swallow eggs is influenced by laying order, maternal infection and paternal ornamentation. Proc R Soc Lond B Biol Sci. 2002a;269:1729-33.

Saino N, Dall'Ara P, Martinelli R, Møller A. Early maternal effects and antibacterial immune factors in the eggs, nestlings and adults of the barn swallow. J Evol Biol. 2002b;15:735-43.

Schwabl H. Yolk is a source of maternal testosterone for developing birds. Proc Nat Acad Sci USA. 1993:90:11446-50.

Schwabl H. A hormonal mechanism for parental favouritism. Nature. 1997;386:231.

Shawkey MD, Kosciuch KL, Liu M, Rohwer FC, Loos ER, Wang JM, Beissinger SR Do birds differentially distribute antimicrobial proteins within clutches of eggs? Behav Ecol. 2008;19:920-7.

Stoleson SH, Beissinger SR. Hatching asynchrony and the onset of incubation in birds, revisited. New York: Plenum Press; 1995.

Tella JL. The evolutionary transition to coloniality promotes higher blood parasitism in birds. J Evol Biol. 2002;15:32-41.

Trziszka T. Lysozyme and its functions in the egg. Arch Geflugelk. 1994:58:49-54.

Vinuela J. Adaptation vs. constraint: intraclutch egg-mass variation in birds. J Anim Ecol. 1997:66:781-92.

\section{Submit your next manuscript to BioMed Central and take full advantage of:}

- Convenient online submission

- Thorough peer review

- No space constraints or color figure charges

- Immediate publication on acceptance

- Inclusion in PubMed, CAS, Scopus and Google Scholar

- Research which is freely available for redistribution

Submit your manuscript at

www.biomedcentral.com/submit

() Biomed Central 